\title{
Avaliação da eqüidade da Previdência no meio rural do Brasil ${ }^{1}$
}

\author{
Ana Cecília Kreter ${ }^{2}$ \\ Carlos José Caetano Bacha ${ }^{3}$
}

Resumo: Este trabalho avalia a eqüidade do sistema brasileiro de aposentadorias pagas no meio rural, dando ênfase à década de 1990. Entendese como eqüidade a distribuição de aposentadorias sem viés de cor (ou raça), sexo e nível de educação. Motivado pela Constituição Federal de 1988, as Leis no 8.212 e no 8.213, de 1991 permitiram que homens (com 60 anos de idade ou mais) e mulheres (com 55 anos de idade ou mais) que tivessem comprovado exercício da atividade rural pudessem obter aposentadoria de um salário mínimo, mesmo não tendo contribuído com o sistema previdenciário. Tais mudanças foram significativas, pois igualaram os direitos de mulheres e homens e fixaram um valor mínimo das aposentadorias. Usando a análise tabular de microdados da PNAD (para os anos de 1992, 1996 e 1999) o trabalho comprova que essa nova sistemática previdenciária permitiu o aumento da renda per capita dos aposentados no meio rural, sem causar aumento da desigualdade da distribuição de renda. A mesma análise tabular dos dados sugere a presença de vieses na concessão das aposentadorias em favor de homens (em relação às mulheres), dos brancos (em relação aos negros) e dos mais instruídos (em relação aos menos instruídos), o que foi estatisticamente comprovado através da estimativa do modelo próbite. O trabalho se en-

\footnotetext{
${ }^{1}$ Este artigo baseia-se na dissertação de mestrado da primeira autora, orientada pelo co-autor do artigo.

${ }^{2}$ Mestre em Economia Aplicada pela ESALQ/USP.

${ }^{3}$ Professor Titular da ESALQ/USP. cjcbacha@esalq.usp.br
} 
cerra sugerindo algumas medidas que possam minimizar essa ineqüidade na distribuição das aposentadorias pagas no meio rural.

Palavras-chave: previdência social, meio rural, equidade, Brasil.

\section{Classificação JEL: H 55, Q 10}

Abstract: This paper evaluates the equality of the Brazilian system of pensions paid in rural areas during the 1990s. The equality implies equal access to the social security benefits, regardless ethnic, sex and education differences among retired persons. Basing on 1988 Federal Constitution, Laws 8,212 and 8,213, both from 1991, have instituted the old age pension equal to one minimum wage for men (60 years or older) and for women (55 years or older) if they can prove they were rural workers. These old citizens can retire without any contribution to the social security system. The new norms were important in rural areas because they guarantee equal rights among men and women and increased the value of pensions. Using 1992, 1996 and 1999 PNAD microdatas organized in tables, this paper pointed out that the social security system contributed for the per capita income growth of elderly retired people who lives in rural areas, without enlarging the income distribution inequality. PNAD microdatas organized in tables also indicate that males, white people, and those with higher formal education had an easier access to pension than females, black people and those with lower formal education. These results were confirmed by the Probit model estimated. The paper finishes with some suggestions to improve the equality of pensions paid in rural areas.

Key words: social security, rural area, equality, Brazil.

JEL Classification: $H$ 55, Q 10

\section{Introdução}

O objetivo deste trabalho é avaliar a eqüidade do sistema brasileiro de aposentadorias pagas no meio $\mathrm{rural}^{4}$, dando ênfase à déca-

${ }^{4}$ Nesta análise não estão sendo considerados os pensionistas, apenas os aposentados. 
da de 1990 e, no caso dos aposentados por idade, às mudanças legais ocorridas a partir da Constituição Federal de 1988. Entendese por eqüidade a distribuição das aposentadorias sem viés por sexo, por cor (ou raça) e por grau de escolaridade dos beneficiários.

De um modo geral, a previdência social pode ser estruturada através do sistema de capitalização ou através do sistema de repartição. No sistema de capitalização, as contribuições dos trabalhadores na ativa criam um fundo de participação que servirá de base para o seu benefício a receber no futuro. Já no sistema de repartição, os trabalhadores na ativa financiam os aposentados do mesmo período. E é esta segunda forma a utilizada pelo Brasil nas últimas décadas, inclusive a utilizada no período proposto para a análise neste trabalho.

A previdência social, juntamente com a saúde e a assistência social, pertence à Seguridade Social, que é responsável por um conjunto integrado de ações de iniciativa dos poderes públicos e da sociedade ${ }^{5}$. A previdência e a assistência são, atualmente, de responsabilidade do Ministério da Previdência Social (MPS), e a saúde, do Ministério da Saúde (MS).

No Brasil, os trabalhadores rurais podem participar da previdência social através da contribuição regular para o Instituto Nacional do Seguro Social (INSS) ou podem participar como segurados especiais, desvinculando a aposentadoria da contribuição compulsória. No segundo caso, esses trabalhadores têm que provar o exercício de sua atividade, a partir de certa idade (55 anos para mulheres e 60 anos para homens), obtendo, dessa forma, a aposentadoria por idade no valor de um salário mínimo, independentemente de terem contribuído ao INSS durante sua vida laboral. Tal benefício vigorará até meados de 2006. A partir de então será exigido do candidato(a) a esse benefício um número mínimo de meses de contribuição que, embora seja inferior ao exigido dos trabalhadores da zona urbana, poderá diminuir o número de deferimentos.

Os beneficiários do Regime Geral da Previdência Social (RGPS) são classificados em segurados e dependentes, sendo segurados obrigatórios os empregados, os empregados domésticos, os contribuintes individuais, os trabalhadores avulsos e os segurados especiais (artigo 11ํㅡㅁ

${ }^{5}$ Definição baseada no artigo 1ํ da Lei de Custeio da Seguridade Social. 


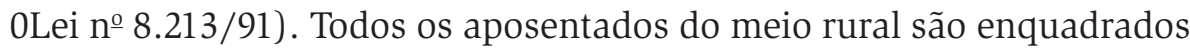
como segurados obrigatórios, sendo que os beneficiários da aposentadoria por idade e da aposentadoria por invalidez fazem parte dos chamados segurados especiais, ou seja, fazem parte daqueles que recebem os benefícios através da comprovação do exercício de atividade rural.

Dentre os princípios e objetivos da Lei de Benefícios da Previdência Social (Lei no ${ }^{\circ}$.213/91) encontra-se no artigo $2^{\circ}$, inciso II, a "uniformidade e equivalência dos benefícios e serviços às populações urbanas e rurais", o que possibilitou, a partir de 1991, o acesso por parte dos segurados especiais aos seguintes benefícios previdenciários ${ }^{6}$ : aposentadoria por invalidez, aposentadoria por idade, auxílio-doença e auxílio reclusão ou de pensão no valor de um salário mínimo, desde que haja comprovação do "exercício de atividade rural, ainda que de forma descontínua, no período, imediatamente anterior ao requerimento do benefício, igual ao número de meses correspondente à carência do benefício requerido”. Esta carência é válida tanto para os benefícios já citados quanto para a aposentadoria por tempo de contribuição, e leva em consideração "o ano em que o segurado implementou todas as condições necessárias à obtenção do benefício”. Para o ano de 2005, são exigidos 144 meses de comprovação do exercício de atividade rural. Os demais benefícios da Lei no 8.213/91 podem ser concedidos aos segurados especiais, desde que haja contribuição previdenciária facultativa.

Esses mesmos benefícios, para efeito analítico, podem ser agrupados em: aposentadorias, auxílios e pensões. Segundo os dados do MAPS/ IPEA $^{7}$, o número de beneficiários no ano de 1999 da previdência rural foi de 6.439.805, sendo as aposentadorias (por idade e por invalidez) responsáveis por mais de $72 \%$ deste montante, seguidas pelas pensões $(25 \%)$ e pelos auxílios (3\%). Assim, o presente trabalho analisa o primeiro grupo de benefícios, especialmente por ainda ser o de maior relevância dentro do sistema previdenciário brasileiro no campo.

${ }^{6}$ Artigo 39 da Lei no $8.213 / 91$.

${ }^{7}$ O MAPS (Modelo Demográfico-Atuarial de Projeções e Simulações de Reformas Previdenciárias) é um modelo elaborado pelo IPEA e composto pelos módulos demográfico, previdenciário e econômico, baseado nos microdados da DATAPREV. Dois dos grupos estimados pelo módulo previdenciário é o de beneficiários rurais e urbanos. O MAPS distingue-os ainda pelo tipo de benefício recebido e por sexo. Para maiores informações, consultar Beltrão et al. (2000b). 


\section{Revisão bibliográfica}

No exame da literatura sobre previdência social no Brasil, constatou-se que, no mínimo, quatro temas têm sido abordados sobre o tópico deste trabalho. Eles são: $a$ ) a evolução do sistema previdenciário e suas estruturas políticas; $b$ ) a distinção por gênero de benefícios concedidos; c) a discussão entre previdência, bem-estar social e distribuição de renda; e $d$ ) a distinção entre benefícios de contribuição compulsória e não compulsória e as reformas atuais de previdência social. Outro tema relevante é a relação entre distribuição de renda e bem-estar social, utilizando as diferentes medidas de desigualdade e pobreza.

É importante ressaltar ainda que há uma ampla literatura sobre previdência social abordando temas que não são o foco deste trabalho, tais como a relação entre previdência social e déficit público, a relação entre previdência social e seguridade social, entre outros.

Analisando a evolução do sistema previdenciário no Brasil, têm-se os trabalhos de Faro (1992), Delgado \& Schwarzer (2000) e Beltrão et al. (2000a). Em todos eles a ênfase é dada ao grau de descentralização da previdência social durante as primeiras décadas após a sua criação em 1923, e na forma como ocorreu a universalização desse sistema. As mudanças legais avaliadas se estendem, principalmente, até a Constituição de 1988.

Vários autores trabalharam com a análise da distinção de gênero na concessão de benefícios da previdência rural, dentre eles: Deud \& Malvar (1993), Médici et al. (1994), Maccalóz \& Melo (1997) e Melo (2000). Além da discriminação histórico-cultural do trabalho feminino no Brasil, os autores também apontam o sistema previdenciário anterior à Constituição de 1988 como sendo o principal agente excluidor das trabalhadoras rurais. Após a instauração do princípio da universalização na Constituição Federal de 1988, as aposentadorias deixaram de ser concedidas apenas ao chefe ou arrimo de família, abrangendo todas as pessoas que tivessem exercido atividade rural. Assim, numa mesma família mais de uma pessoa passou a ter o direito de requerer a aposentadoria por idade.

Autores como Fausto Neto (1982), Abranches (1992), Delgado (1999) e Delgado \& Cardoso Junior (2000) abordaram o terceiro tema citado sobre o sistema previdenciário brasileiro, isto é, discutiram a melhora do bem-estar social e/ou distribuição de renda através dos benefícios concedidos ao tra- 
balhador rural. Dentre estes benefícios, o que mais impactou na qualidade de vida da população do campo foi a aposentadoria por idade. Os idosos, que na inatividade se encontravam na condição de dependentes, passaram a ser participantes da renda familiar, o que, sob diversos aspectos, causou uma melhora no bem-estar tanto do beneficiário como também de seus familiares. Para mensurar o impacto da previdência rural sobre o bem-estar, Delgado (1999) utilizou como metodologia a aplicação de questionários e de simulações numéricas de um modelo de gerações superpostas.

Abordando especificamente a questão do bem-estar social e da distribuição de renda em relação a toda a população brasileira e não necessariamente restrita à população previdenciária, destacam-se ainda os seguintes autores: Corrêa (1995), Barros et al. (1997), Hoffmann (1998), Hoffmann (2002) e Ferreira (2003). Hoffmann (1998) expõe as diferentes medidas de desigualdade e pobreza, apresentando os índices mais usados e suas aplicações. Corrêa (1995) utiliza alguns destes índices para analisar a distribuição de rendimentos e a pobreza entre as pessoas ocupadas na agricultura brasileira entre 1981 e 1990. Barros et al. (1997) traça um panorama geral do desempenho social no Brasil a partir da década de 1960, observando o comportamento dos níveis de bem-estar, pobreza e desigualdade através da distribuição de renda. Hoffmann (2002) analisa a contribuição dos componentes do rendimento domiciliar para a desigualdade da distribuição do rendimento domiciliar per capita. Fazendo a decomposição do índice de Gini da distribuição deste rendimento para o ano de 1999, o autor conclui que os rendimentos do trabalho principal dão origem à maior parcela do índice de Gini. Ferreira (2003) analisa a participação das aposentadorias e pensões na desigualdade da distribuição de renda entre 1981 e 2001. O autor utiliza como metodologia a decomposição do índice de Gini para determinar a contribuição de cada parcela do rendimento para a desigualdade total, e conclui que a parcela de rendimento das aposentadorias e pensões, para o período analisado, contribuiu para aumentar a desigualdade da distribuição da renda no Brasil em seis dos dezesseis anos analisados.

Alguns autores trabalham com a distinção entre benefícios de contribuição compulsória e não compulsória nos sistemas previdenciários e as reformas atuais da previdência social, dentre eles: James (1998), Schwarzer (2000) e International Social Security Association (2004). Schwarzer (2000) se concentra na distribuição entre benefícios concedi- 
dos a trabalhadores rurais e urbanos. Esta distinção é relevante, principalmente, em países em desenvolvimento, como os latino-americanos. Para países desenvolvidos, a maior preocupação são os trabalhadores estrangeiros. Analisando a nova estrutura do mercado de trabalho, assim como as reformas da previdência social durante as décadas de 1980 e 1990, destacam-se os trabalhos de James (1998) e ISSA (2004).

Considerando-se em conjunto a bibliografia acima citada, constatase que uma das questões sobre a previdência social do Brasil que ainda não foi avaliada completamente é de que forma variáveis como sexo, cor (ou raça) e nível de educação contribuem para a desigualdade na distribuição das aposentadorias pagas no meio rural. Essas são questões abordadas na análise da eqüidade do sistema previdenciário brasileiro, e a busca de evidências motiva a realização deste trabalho.

Para a concretização desse objetivo, o presente artigo compõe-se de mais cinco seções. Na seção 3 são analisadas as principais alterações na previdência social após 1988 e que afetam o período em análise. A seção 4 discute os dados utilizados e expõe a metodologia empregada. A seção 5 avalia os efeitos da previdência rural em aumentar a renda de seus beneficiários e como se comporta a desigualdade da distribuição da renda dos aposentados. A seção 6 evidencia, através da análise tabular e econométrica, possíveis desigualdades na distribuição da aposentadoria rural em termos de cor (raça), sexo e nível de escolaridade dos beneficiários. E, finalmente, a seção 7 apresenta as conclusões do artigo.

\section{Alterações introduzidas na previdência rural a partir da Constituição Federal de 1988}

Em 1988 foi aprovada a última Constituição Federal brasileira, que teve como princípio a universalização da seguridade social ${ }^{8}$, englobando as áreas da saúde, da previdência social e da assistência social. Mudanças significativas foram introduzidas no sistema previdenciário. Apesar dos trabalhadores do meio rural já contarem com uma relativa concessão de benefícios, a previdência rural se encontrava muito aquém se fosse comparada ao sistema já aplicado na zona urbana.

${ }^{8}$ Entende-se por universalização da seguridade social a igualdade de direitos e deveres entre os cidadãos perante a lei. 
Alguns problemas enfrentados pelos trabalhadores rurais passaram a ser mais discutidos, e motivaram a criação das Leis no 8.212 (Plano de Custeio da Seguridade Social) e no 8.213 (Plano de Benefícios da Previdência Social) que entraram em vigor em 1991. Para a previdência rural, o principal objetivo destas Leis era inserir os trabalhadores rurais de maneira ampla no sistema.

Os trabalhadores rurais passaram a participar, então, de forma mais ampla do sistema previdenciário, principalmente, através de dois tipos de benefício: o de contribuição obrigatória e o de contribuição facultativa. No primeiro deles, os trabalhadores rurais trabalham com carteira assinada, contribuem para a previdência social durante suas vidas laborais e gozam da aposentadoria na inatividade, recebendo até $100 \%$ do salário-de-benefício, que pode ser de um (1) salário mínimo ou acima desse valor.

A segunda categoria abrange, principalmente, os trabalhadores rurais classificados como segurados especiais ${ }^{9}$. Na segunda categoria estão sendo considerados os trabalhadores rurais sem carteira assinada, os que participam da agricultura familiar ou da agricultura de subsistência. Estes trabalhadores, apesar de não contribuírem compulsoriamente para a previdência social, têm o direito de receber a aposentadoria por idade ou por invalidez no valor de um salário mínimo, mediante comprovação de exercício na atividade rural, desde que tenham, no mínimo, 60 anos (se homem) ou 55 anos (se mulher).

A nova legislação previdenciária rural ampliou significativamente o número de aposentados no campo. Os aposentados com residência na zona rural passaram de 3.339.122 em 1992 para 5.032.034 em 1999 (acréscimo de 50,7\% nestes sete anos), segundo os dados da Pesquisa Nacional por Amostra de Domicílios (PNAD). E o maior crescimento foi de aposentados que receberam um salário mínimo de rendimento de aposentadoria (considerados neste trabalho como proxy dos aposenta-

${ }^{9}$ De acordo com o artigo 195, inciso III, § 8o da Constituição Federal de 1988 “o produtor, o parceiro, o meeiro e o arrendatário rurais e o pescador artesanal, bem como os respectivos cônjuges, que exerçam suas atividades em regime de economia familiar, sem empregados permanentes, contribuirão para a Seguridade Social mediante a aplicação de uma alíquota sobre o resultado da comercialização da produção e farão jus aos benefícios nos termos da lei”. Vale lembrar que após a Emenda Constitucional no 20/1998 houve a supressão dos garimpeiros deste parágrafo. 
dos por idade). Eles aumentaram de 1.463.854 em 1992 para 4.741.830 em 1999, com aumento de 223,9\% nestes mesmo sete anos.

Para uma melhor compreensão das mudanças ocorridas com as Leis no 8.212/91 e no 8.213/91, referentes aos segurados especiais, o Quadro 1 apresenta uma análise comparativa da participação no sistema previdenciário desses trabalhadores rurais antes e depois da nova legislação.

Quadro 1 - Principais mudanças na regulamentação da previdência rural após a Constituição Federal de 1988

\begin{tabular}{|l|l|}
\hline \multicolumn{1}{|c|}{ Como Era } & \multicolumn{1}{c|}{ O Que Mudou } \\
\hline $\begin{array}{l}\text { Teto de benefício de, no máximo, meio } \\
\text { salário mínimo para as aposentadorias, } \\
\text { e de 30\% do salário mínimo para as } \\
\text { pensões; }\end{array}$ & $\begin{array}{l}\text { Teto do benefício no valor de um salário } \\
\text { mínimo; }\end{array}$ \\
\hline $\begin{array}{l}\text { Aposentadoria por idade concedida aos } \\
65 \text { anos; }\end{array}$ & $\begin{array}{l}\text { Aposentadoria por idade concedida aos } \\
55 \text { anos para as mulheres, e aos } 60 \text { anos } \\
\text { para os homens; }\end{array}$ \\
\hline $\begin{array}{l}\text { Concessão do benefício apenas ao chefe } \\
\text { ou arrimo de família. }\end{array}$ & $\begin{array}{l}\text { Igualdade de direitos entre os } \\
\text { trabalhadores e trabalhadoras rurais. }\end{array}$ \\
\hline
\end{tabular}

Fonte: Brasil (1988)

Através do Quadro 1, observa-se que a primeira alteração significativa se refere ao teto de benefício. Enquanto as aposentadorias passaram de meio para um salário mínimo ${ }^{10}$, as pensões tiveram um salto ainda maior, saindo de $30 \%$ para também um salário mínimo. Assim, os rendimentos daqueles que já estavam incluídos no sistema previdenciário, no mínimo, dobraram.

Outro ponto importante a ser destacado no Quadro 1 é a mudança na idade mínima para se aposentar por idade. Até 1991, a aposentadoria era concedida a qualquer trabalhador rural ao completar 65 anos de idade. Após a promulgação das Leis ํㅡㅇ 8.212 e ํㅡ 8.213, em 1991, a idade mínima para requerer a aposentadoria por idade passou a ser 60 anos para os homens, e 55 anos para as mulheres. Se as idades mínimas dos trabalhadores rurais forem comparadas com as vigentes para os traba-

${ }^{10}$ Artigo $201 \S 2^{\circ}$ CRFB. 
lhadores urbanos, constata-se que os trabalhadores rurais têm o direito a se aposentar cinco anos antes do que os trabalhadores urbanos.

Se a aposentadoria por idade viabilizou uma crescente participação da população rural no sistema previdenciário, é através da análise por gênero deste benefício que as mudanças na legislação ficam ainda mais nítidas. A aposentadoria por idade já existia antes de 1988, porém a trabalhadora rural perdia o direito de se aposentar a partir do momento em que ela passava a viver maritalmente com seu cônjuge. Em outras palavras, a previdência social no campo concedia o benefício apenas ao chefe ou arrimo de família. A equiparação das condições de acesso para homens e mulheres trabalhadores rurais fez com que, de fato, houvesse igualdade de gênero na concessão dos benefícios previdenciários.

Atualmente, a comprovação do exercício da atividade rural, mesmo que de forma descontínua, é condição suficiente, e não apenas necessária, para o requerimento da aposentadoria por idade, permanecendo assim até 2006. A concessão da aposentadoria por idade no valor de um salário mínimo é garantida para aqueles com idade mínima exigida pela Lei e comprovação do exercício da atividade rural no período anterior ao requerimento do benefício, mesmo que descontinuamente. A partir de 2006 a contribuição por parte do trabalhador rural passa a ser compulsória. Para o trabalhador que queira contribuir, o número de meses de contribuição é de 144 em 2005. Esse número continuará crescente, aumentando de seis em seis meses a cada ano até chegar a 180 meses de contribuição, ou 15 anos, em 2011.

\section{Dados utilizados e metodologia empregada}

Esta seção apresenta os dados a serem utilizados (item 4.1) e descreve a população em consideração (item 4.2). Em seguida, apresenta-se a metodologia empregada na análise, em especial o modelo econométrico usado para mensurar o impacto da escolaridade, da cor (ou raça) e do sexo na concessão das aposentadorias recebidas pela população em análise (item 4.3). 


\subsection{As fontes de dados utilizadas}

A fim de analisar a eqüidade no sistema de aposentadorias dos residentes na zona rural brasileira foram utilizados os microdados da PNAD (Pesquisa Nacional por Amostra de Domicílios) disponibilizados pelo Instituto Brasileiro de Geografia e Estatística (IBGE).

Como o presente trabalho se restringe à análise da década de 1990, foram selecionados os anos de 1992, 1996 e 1999 para a coleta de dados. A escolha destes anos foi baseada na necessidade de se possuir intervalos próximos e, para efeito comparativo, a mesma metodologia ${ }^{11}$.

Embora os dados das PNADs possuam uma ampla amostra e sejam de boa qualidade, é importante destacar que, em relação à classificação do domicílio, considerou-se apenas aqueles localizados na zona rural. Seu território inclui toda a região que excede as cidades (sedes municipais), as vilas (sedes distritais) e as áreas urbanas isoladas. Por outro lado, essa consideração exclui da análise os estados da antiga região Norte (Acre, Amapá, Amazonas, Pará, Rondônia e Roraima) por não terem dados disponíveis.

Os dados utilizados também não consideram a totalidade dos aposentados da previdência rural. Em relação aos beneficiários da previdência rural e por idade, sabe-se que nem todos permaneceram com a residência próxima do antigo local de trabalho. Alguns, ainda, nunca moraram no campo. Segundo Delgado \& Cardoso Jr. (2000), 49\% dos beneficiários da previdência rural (aposentados e pensionistas) na região Sul do Brasil permaneceram com residência na zona rural ${ }^{12}$. Para a região Nordeste esta percentagem foi ainda menor (45,3\%). Apesar dos resultados significativos do país, acredita-se que, na média, aproximadamente a metade da população aposentada por idade pelo sistema de previdência rural resida na zona rural, o que significa que as conclusões deste trabalho referem-se a esse contingente.

${ }^{11}$ No final da década de 1980 e início da década de 1990, o Censo demográfico foi realizado em 1991 e não em 1990, como era o esperado. Por este motivo, o primeiro ano escolhido para a análise foi 1992.

12 Resultado baseado na Pesquisa Avaliação Socioeconômica e Regional da Previdência Rural - Fase II, realizada em 1998 nas regiões Nordeste e Sul do Brasil, as mais representativas no sistema de previdência rural. 
Três categorias distintas de pessoas aposentadas por um instituto de previdência público estão sendo consideradas. A primeira delas inclui todos os aposentados, com idade igual a 55 anos ou superior, se mulheres, e igual a 60 anos ou superior, se homens, com residência na zona rural, independente do valor da aposentadoria. A segunda categoria é um subgrupo da primeira, considerando os mesmos homens e mulheres, porém, determinando que seus rendimentos de aposentadoria sejam de um salário mínimo. Este contingente é uma proxy dos aposentados por idade (na previdência rural) que ainda residem na zona rural. Isto porque ao completarem 55 e 60 anos, respectivamente, trabalhadoras e trabalhadores rurais têm direito a requerer a aposentadoria por idade igual a um salário mínimo mediante comprovação de atividade rural. Vale lembrar que dentre todas as aposentadorias da previdência rural, a mais significativa, como será mostrado adiante, é a aposentadoria por idade. A terceira categoria de aposentados também considera a mesma faixa etária para homens ( 60 anos de idade ou mais) e mulheres (55 anos de idade ou mais) residentes na zona rural, porém, inclui apenas aqueles que recebem rendimentos de aposentadoria superiores a um salário mínimo. Assim, é possível distinguir os aposentados por idade, dos demais aposentados e verificar suas singularidades dentro do que se objetiva nesta análise.

Os microdados das PNADs permitem uma análise, por categoria de idosos(as), dos seguintes aspectos:

- da melhoria da renda familiar através da concessão de aposentadorias aos residentes na zona rural; e

- da evolução do número de aposentados acima definidos, analisando a classificação por sexo, por cor (ou raça) e por grau de escolaridade.

\subsection{A população de idosos na zona rural}

A Tabela 1 apresenta o número absoluto de idosos(as) que se declararam aposentados(as) e não aposentados(as) ${ }^{13}$ por um instituto de previdência público (homens com 60 anos ou mais e mulheres com 55

\footnotetext{
${ }^{13}$ O número absoluto do total de aposentados(as) e de não aposentados(as) foi obtido através das variáveis V912502 (1992) e V9122 (1996 e 1999).
} 
anos ou mais) residentes na zona rural. Os aposentados foram divididos ainda entre os que recebiam um salário mínimo de rendimento de aposentadoria e os que recebiam mais de um salário mínimo de mesmo rendimento durante o período analisado ${ }^{14}$.

Tabela 1 - Distribuição de aposentados e não aposentados com residência na zona rural, por sexo - Brasil - anos selecionados

\begin{tabular}{ccccc}
\hline \multirow{2}{*}{ Sexo } & \multirow{2}{*}{ Grupo $\begin{array}{c}\text { Rendimento de } \\
\text { Aposentadoria }\end{array}$} & 1992 & 1996 & 1999 \\
\cline { 3 - 5 } & & & & \multicolumn{3}{c}{ Ano } \\
\multirow{3}{*}{ Homens } & total de aposentados & 1.868 .854 & 2.230 .298 & 2.447 .900 \\
& $=1$ sal. mín. & 828.316 & 1.917 .238 & 2.251 .500 \\
& > 1 sal. mín. & 875.446 & 210.674 & 186.332 \\
& total de não aposentados & 845.646 & 637.520 & 618.248 \\
& total de idosos & 2.714 .500 & 2.867 .818 & 3.066 .148 \\
\hline \multirow{3}{*}{ Mulheres } & total de aposentadas & 1.470 .268 & 2.421 .150 & 2.584 .134 \\
& $\quad=1$ sal. mín. & 635.538 & 2.193 .534 & 2.490 .330 \\
& total de não aposentadas & 2.185 .469 & 1.367 .782 & 1.366 .200 \\
& total de idosas & 3.655 .737 & 3.788 .932 & 3.950 .334 \\
\hline
\end{tabular}

Fonte: elaborado a partir de IBGE (1992, 1996 e 1999)

Nota: em todos os grupos estão sendo considerados os homens com 60 anos ou mais, e as mulheres com 55 anos ou mais

A população de aposentados em análise abrange um total de 3.339.122 aposentados em 1992, sendo 1.470.268 mulheres e 1.868.854 homens. Para os demais anos, esse total é de 2.421 .150 mulheres e 2.230 .298 homens aposentados em 1996, e 2.584.134 mulheres e 2.447.900 homens aposentados em 1999. Dessa população em análise, observa-se que os aposentados de ambos os sexos que receberam um salário mínimo de rendimento de aposentadoria foram crescentes nos anos 1992, 1996 e 1999 (Tabela 1), enquanto o número de aposentados que receberam mais de um salário mínimo de mesmo rendimento foi decrescente ${ }^{15}$.

14 Para selecionar os aposentados pelo valor de seus rendimentos de aposentadoria, utilizaram-se as variáveis V0912502 (1992) e V1252 (1996 e 1999).

${ }^{15}$ Estes dados referem-se apenas aos beneficiários da previdência social. Não é objetivo do trabalho analisar os contribuintes do sistema previdenciário. 
Através da Tabela 1, observa-se ainda que, em 1992, a maior parte dos homens e mulheres aposentados residentes na zona rural recebiam mais de um salário mínimo de rendimento de aposentadoria. Isto se inverte a partir de 1996. Os dados da Tabela 1 ressaltam também que os grupos de aposentados(as) têm evoluções distintas e, assim, a análise da eqüidade das aposentadorias pagas no meio rural deve ser feita para, no mínimo, estas duas categorias.

Para diagnosticar se os aposentados que recebem um salário mínimo e que vivem no meio rural são ou não segurados especiais, pode-se separar esses aposentados em, no mínimo, duas categorias. A primeira delas considera as pessoas que se aposentaram antes da idade mínima para o requerimento da aposentadoria por idade, e que estavam recebendo rendimento de aposentadoria no valor de um salário mínimo de um instituto de previdência público. Para efeito comparativo, foram consideradas na primeira categoria as pessoas do sexo masculino entre 55 e 60 anos e do sexo feminino entre 50 e 55 anos, ambos com residência rural. A segunda categoria se refere aos aposentados do sexo masculino com idade igual ou superior a 60 anos e do sexo feminino com idade igual ou superior a 55 anos, também com residência na zona rural e rendimento de aposentadoria no valor de um salário mínimo. Neste caso, foram incluídas as pessoas que já deveriam estar aposentadas por idade.

Para analisar a evolução da inclusão dos trabalhadores rurais participantes do sistema de aposentadoria por idade, dividiram-se as mulheres em cinco grupos etários, e os homens, em quatro, baseando-se nas duas categorias citadas acima. O primeiro grupo etário considerou a primeira categoria citada no parágrafo anterior, qual seja, o contingente que já estava recebendo algum tipo de aposentadoria antes da idade mínima de se aposentar por idade ${ }^{16}$. Os demais grupos se referem aos aposentados da segunda categoria. As Tabelas 2 e 3 apresentam as percentagens de aposentados e aposentadas, respectivamente, com rendimento de aposentadoria igual a um salário mínimo e residência na zona rural em relação ao total de idosos com a mesma faixa etária e local de residência. Assim, em 1992 apenas 3\% dos homens entre 55 e

${ }^{16}$ No contingente analisado não estão sendo considerados os pensionistas dos institutos de previdência públicos. 
59 anos estavam aposentados (Tabela 2), bem como $2 \%$ das mulheres de 50 a 54 anos (Tabela 3). Essas percentagens são crescentes à medida que a faixa etária aumenta e de um ano a outro.

Tabela 2 - Percentagem de homens aposentados* com residência na zona rural - Brasil - anos selecionados

\begin{tabular}{ccccc}
\hline \multirow{2}{*}{ Ano } & \multicolumn{5}{c}{ Faixa Etária } \\
\cline { 2 - 5 } & $55-59$ & $60-64$ & $65-69$ & $\geq 70$ \\
\hline 1992 & 3 & 19 & 55 & 85 \\
1996 & 6 & 44 & 78 & 94 \\
1999 & 8 & 55 & 78 & 95 \\
\hline
\end{tabular}

Fonte: elaborado a partir de IBGE (1992, 1996 e 1999)

* Estão sendo considerados os rendimentos de aposentadoria igual a um salário mínimo

Tabela 3 - Percentagem de mulheres aposentadas* com residência na zona rural - Brasil - anos selecionados

\begin{tabular}{cccccc}
\hline \multirow{2}{*}{ Ano } & \multicolumn{5}{c}{ Faixa Etária } \\
\cline { 2 - 6 } & $50-54$ & $55-59$ & $60-64$ & $65-69$ & $\geq 70$ \\
\hline 1992 & 2 & 7 & 12 & 23 & 47 \\
1996 & 4 & 38 & 61 & 66 & 77 \\
1999 & 4 & 41 & 65 & 74 & 77 \\
\hline
\end{tabular}

Fonte: elaborado a partir de IBGE (1992, 1996 e 1999)

* Estão sendo considerados os rendimentos de aposentadoria igual a um salário mínimo

Para os aposentados com 70 anos de idade ou mais, com rendimentos provenientes do sistema de aposentadorias igual a um salário mínimo, a participação chegou a resultados superiores a $75 \%$, com exceção apenas das mulheres em 1992. A baixa participação das mulheres em 1992, se comparada aos demais grupos, pode ser explicada pela mudança na legislação (como visto na seção 3). Este resultado sugere que o aumento ocorrido a partir dos 60 anos, para os homens (Tabela 2), e a partir dos 55 anos, para as mulheres (Tabela 3), pode ser conseqüência da concessão da aposentadoria por idade.

Desta forma, justifica-se a utilização das duas categorias de aposentados com residência na zona rural: os que recebem um salário mínimo como rendimento de aposentadoria (proxy dos aposentados por idade), 
e os que recebem mais de um salário mínimo do mesmo rendimento ${ }^{17}$. Desse modo, busca-se diagnosticar a presença ou não de eqüidade entre os aposentados por idade e outros aposentados, ambos com residência na zona rural.

\subsection{Metodologia empregada}

Inicialmente será realizada a análise tabular dos microdados das PNADs, avaliando a evolução do rendimento per capita e da desigualdade da distribuição da renda dos aposentados e não aposentados no meio rural (seção 5). Procurar-se-á com tal análise verificar o quanto a previdência rural implicou melhora da renda de seus beneficiários e se isso implicou ou não deterioração da distribuição da renda. Para avaliar esse último aspecto, o índice de Gini será calculado.

A análise tabular dos dados das PNADs também será empregada para identificar o perfil dos aposentados com residência na zona rural segundo o nível de escolaridade, a cor (ou raça) e o sexo (seção 6). Após isso, o impacto de cada uma dessas variáveis na obtenção da aposentadoria será avaliado econometricamente, empregando modelo Próbite. Nesse modelo, a variável dependente é a condição do residente na zona rural, a partir dos 55 anos, se mulher, e dos 60 anos, se homem, estar aposentado ou não, assumindo um (1) quando ele está aposentado e zero (0) quando ele não está aposentado. Entre os aposentados serão aplicadas regressões distintas para aqueles com rendimento de aposentadoria igual a um salário mínimo e maior que um salário mínimo.

A equação genérica a ser estimada é a seguinte:

$$
Y i=f(E s, C r, S x)
$$

\footnotetext{
${ }^{17}$ Considerou-se um salário mínimo os rendimentos de aposentadoria entre Cr $\$ 500.000,00$ e $\operatorname{Cr} \$ 550.000,000$, em 1992 , entre $R \$ 110,00$ e $R \$ 120,00$, em 1996 , e entre $R \$ 130,00$ e R\$140,00, em 1999, incluindo estes valores. Os valores do salário mínimo para esses anos eram de: $\operatorname{Cr} \$ 522.186,94$ (1992), $\mathrm{R} \$ 112,00$ (1996) e $\mathrm{R} \$ 136,00$ (1999). Utilizaram-se intervalos para esses valores porque a PNAD não informa centavos, além dos entrevistados tenderem a responder o valor de suas rendas aproximadas. Essa tendência pode ser observada no ano de 1995, quando o salário mínimo foi de $\mathrm{R} \$ 100,00$. O número de pessoas que responderam receber precisamente o equivalente a um salário mínimo nesse ano foi muito superior aos demais anos.
} 
Onde:

$Y i=$ Binária indicando se o idoso residente na zona rural é aposentado por um instituto de previdência público ou não

$E s=$ Número de anos de estudo completos

$\mathrm{Cr}=$ Binária indicando se o idoso é branco ou negro

$S x=$ Binária indicando se o idoso é homem ou mulher

Como foi citado anteriormente, está sendo considerada como variável dependente a condição do idoso residente na zona rural ser aposentado $(Y=1)$ ou não $(Y=0)$ por um instituto de previdência público durante a década de 1990. As variáveis explicativas são: o número de anos de estudo completos, a cor (ou raça) e o sexo, sendo as duas últimas também binárias.

\section{Efeitos sobre a renda familiar média per capita e a desigualdade da renda familiar proveniente da aposentadoria no meio rural}

Esta seção analisa o resultado do cálculo do índice de Gini para a distribuição da renda familiar para os diferentes grupos de idosos. Utilizou-se como variável de referência a renda familiar per capita na mensuração do grau de desigualdade da distribuição da renda entre os aposentados e os não aposentados residentes na zona rural. A Tabela 4 apresenta esses resultados e a média do rendimento familiar per capita em salários mínimos, distinguindo a vinculação ou não de cada idoso ao sistema de aposentadorias e, no caso dos aposentados, através do rendimento de aposentadoria. Vale lembrar que também foram considerados os grupos "total de aposentados" e "total de não aposentados".

Na Tabela 4, cinco aspectos devem ser ressaltados. O primeiro deles é que as medidas de desigualdade da distribuição de renda são menores entre os aposentados vivendo no meio rural, quando os mesmos são comparados aos não aposentados da zona rural. Por exemplo, em 1999 o Gini da distribuição da renda familiar per capita dos aposentados foi 0,441, e dos não aposentados, 0,581 . Isto se mantém, de um modo geral, quando se compara o índice de Gini das rendas familiares per capita de aposentados recebendo mais de um salário mínimo e os não aposentados. Em 
termos de ordenação crescente do índice de Gini, tem-se: aposentados com rendimento de aposentadoria igual a um salário mínimo, total de aposentados, aposentados com rendimento de aposentadoria maior que um salário mínimo e não aposentados. Nesta última análise, apenas dois grupos foram exceção: as mulheres nos anos de 1996 e 1999.

O segundo aspecto a ser ressaltado é que a desigualdade da distribuição da renda tendeu a aumentar de 1992 a 1996, e retrocedeu de 1996 a 1999. Esta tendência é válida tanto para os aposentados como para os não aposentados. Somente as mulheres não aposentadas foram exceção.

O terceiro aspecto que se nota na Tabela 4 é que a renda familiar média per capita de todos os homens e mulheres aposentados é sistematicamente maior que a dos não aposentados. Observaram-se duas exceções para esta tendência: entre os homens no ano de 1996, e entre as mulheres no ano de 1999.

Este resultado parece óbvio, já que qualquer rendimento acrescido à renda familiar vai elevar a mesma. Mas, o importante, nesse caso, é destacar o papel do idoso na sua composição. Com a aposentadoria por idade, o idoso deixou de ser dependente e passou a ser participante da renda familiar, representando, muitas vezes, o único contribuinte em diversas famílias brasileiras. Assim, a abrangência do benefício previdenciário vai muito mais além do que apenas os idosos residentes na zona rural.

O quarto aspecto é que a renda média familiar per capita do "total de aposentados" e dos aposentados com rendimento de aposentadoria igual a um salário mínimo de ambos os sexos aumentou entre 1992 e 1996, porém, esta mesma renda diminuiu entre 1996 e 1999. Mas, comparando-se as rendas de 1999 e 1992, percebe-se que a de 1999 continuou sendo a mais alta. Os aposentados com rendimento de aposentadoria maior que um salário mínimo tiveram incrementos progressivos na renda média familiar per capita, tanto de 1992 para 1996, quanto de 1996 para 1999. Entre os homens não aposentados houve um incremento na renda média de 1992 para 1996, mas uma queda de 1996 para 1999. Já entre as mulheres, houve incremento nas duas passagens.

Finalmente, comparando-se os índices de Gini entre famílias urbanas e rurais, observa-se que as do meio rural apresentaram menor desigualdade e níveis mais baixos de renda familiar per capita.

Os resultados da presente seção não geram dúvida de que o sistema 
previdenciário permitiu melhorar os níveis de renda no campo, mas não implicou deterioração da distribuição de renda em relação ao grupo dos não aposentados. Na próxima seção avalia-se de que forma a condição do idoso ser branco ou negro, ser instruído ou analfabeto e ser homem ou mulher influencia na concessão da aposentadoria.

Tabela 4 - Índice de Gini e média do rendimento familiar per capita dos aposentados e não aposentados com residência na zona rural, por sexo - Brasil - anos selecionados

\begin{tabular}{|c|c|c|c|c|c|c|c|c|}
\hline \multirow[b]{2}{*}{ Sexo } & \multirow[b]{2}{*}{ Área } & \multirow[b]{2}{*}{ Grupo } & \multicolumn{2}{|c|}{1992} & \multicolumn{2}{|c|}{1996} & \multicolumn{2}{|c|}{1999} \\
\hline & & & Gini & $\begin{array}{l}\text { Renda } \\
\text { Média }^{1} \\
\end{array}$ & Gini & $\begin{array}{l}\text { Renda } \\
\text { Média }^{1} \\
\end{array}$ & Gini & $\begin{array}{l}\text { Renda } \\
\text { Média }^{1}\end{array}$ \\
\hline \multirow[t]{7}{*}{ Homens } & \multirow{5}{*}{ 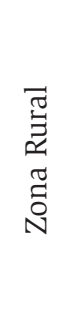 } & $\begin{array}{c}\text { total de } \\
\text { aposentados }\end{array}$ & 0,435 & 0,925 & 0,451 & 1,255 & 0,441 & 1,250 \\
\hline & & $\begin{array}{l}\text { aposent. = } 1 \text { sal. } \\
\text { mín. }\end{array}$ & 0,379 & 0,966 & 0,409 & 1,121 & 0,375 & 1,060 \\
\hline & & $\begin{array}{c}\text { aposent. > } 1 \text { sal. } \\
\text { mín. }\end{array}$ & 0,469 & 0,974 & 0,531 & 2,635 & 0,524 & 3,458 \\
\hline & & não aposentados & 0,588 & 0,680 & 0,674 & 1,456 & 0,581 & 1,168 \\
\hline & & total zona rural & 0,488 & 0,847 & 0,512 & 1,300 & 0,471 & 1,233 \\
\hline & \multicolumn{2}{|c|}{ zona urbana ${ }^{2}$} & 0,575 & 1,979 & 0,618 & 3,218 & 0,623 & 3,183 \\
\hline & \multicolumn{2}{|c|}{ Brasil $^{2}$} & 0,581 & 1,695 & 0,622 & 2,768 & 0,622 & 2,729 \\
\hline \multirow[t]{7}{*}{ Mulheres } & \multirow{5}{*}{ 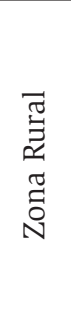 } & $\begin{array}{c}\text { total de } \\
\text { aposentadas }\end{array}$ & 0,377 & 0,920 & 0,452 & 1,287 & 0,400 & 1,243 \\
\hline & & $\begin{array}{l}\text { aposent. = } 1 \text { sal. } \\
\text { mín. }\end{array}$ & 0,331 & 1,016 & 0,389 & 1,139 & 0,344 & 1,112 \\
\hline & & $\begin{array}{l}\text { aposent. > } 1 \text { sal. } \\
\text { mín. }\end{array}$ & 0,382 & 0,922 & 0,692 & 4,451 & 0,560 & 4,826 \\
\hline & & não aposentadas & 0,505 & 0,732 & 0,553 & 1,093 & 0,558 & 1,237 \\
\hline & & total zona rural & 0,458 & 0,807 & 0,491 & 1,215 & 0,461 & 1,241 \\
\hline & \multicolumn{2}{|c|}{ zona urbana ${ }^{2}$} & 0,558 & 1,878 & 0,607 & 3,125 & 0,596 & 2,920 \\
\hline & \multicolumn{2}{|c|}{ Brasil $^{2}$} & 0,558 & 1,666 & 0,612 & 2,784 & 0,597 & 2,627 \\
\hline
\end{tabular}

Fonte: elaborado a partir de IBGE (1992, 1996 e 1999)

${ }^{1}$ Média da renda familiar per capita em salários mínimos

${ }^{2}$ Não foi considerada a região Norte 


\section{Distribuição das aposentadorias pagas no meio rural segundo a cor (ou raça) e a escolaridade dos beneficiados}

Esta seção faz uma análise tabular e econométrica do perfil dos aposentados e dos não aposentados residentes na zona rural por cor (ou raça) e nível de escolaridade, ao longo da década de 1990. Procurase diagnosticar a possibilidade de existir favorecimento na concessão destas aposentadorias segundo a cor (ou raça) dos beneficiados (item 6.1) e/ou o grau de escolaridade dos mesmos (item 6.2). Em seguida, mede-se o impacto destas variáveis e do sexo sobre a condição do idoso estar ou não aposentado, utilizando o modelo Próbite (item 6.3).

\subsection{Análise da cor (ou raça) dos aposentados com residência na zona rural}

As tabelas de classificação dos grupos selecionados segundo sua cor (ou raça) obedecem, inicialmente, a classificação adotada pelas PNADs, a saber: branca, preta, amarela, parda e indígena, sendo que a parda inclui as pessoas que se declararam mulatas, caboclas, cafuzas, mamelucas ou mestiças de preto com outra cor (ou raça). Após a identificação dos principais grupos serão consideradas como negras as pessoas que se declararam de cor preta ou parda.

A Tabela 5 apresenta os aposentados residentes na zona rural com rendimento de aposentadoria igual a um salário mínimo e maior que um salário mínimo, ao longo da década de 1990, por sexo e cor. Nessa tabela, observa-se que a soma das percentagens em cada grupo e para cada ano é igual a $100 \%$. Assim, é possível verificar quais são os grupos mais representativos entre os aposentados durante a década. Por exemplo, em 1992, 53\% dos homens aposentados com residência na zona rural e rendimento de aposentadoria igual a um salário mínimo eram brancos, 9\% pretos e 37\% pardos. Para o ano de 1996 houve uma queda de oito pontos percentuais na participação de brancos e um aumento de mesma magnitude entre os pardos. Essa distribuição teve valores semelhantes em 1999. 
Tabela 5 - Distribuição percentual de aposentados com residência na zona rural, por sexo e cor (ou raça) - Brasil - anos selecionados

\begin{tabular}{|c|c|c|c|c|c|}
\hline \multirow{3}{*}{ Ano } & \multirow{3}{*}{ Cor } & \multicolumn{4}{|c|}{ Renda deAposentadoria } \\
\hline & & \multicolumn{2}{|c|}{ Homens } & \multicolumn{2}{|c|}{ Mulheres } \\
\hline & & $=1$ sal. $\min$. & $>1$ sal. min. & $=1$ sal. $\min$. & $>1$ sal. min. \\
\hline \multirow[t]{6}{*}{1992} & indígena & 0 & 0 & 0 & 0 \\
\hline & branca & 53 & 33 & 50 & 34 \\
\hline & preta & 9 & 8 & 11 & 10 \\
\hline & amarela & 1 & 0 & 1 & 0 \\
\hline & parda & 37 & 59 & 38 & 56 \\
\hline & Total & 100 & 100 & 100 & 100 \\
\hline \multirow[t]{6}{*}{1996} & indígena & 0 & 0 & 0 & 0 \\
\hline & branca & 45 & 58 & 48 & 45 \\
\hline & preta & 9 & 7 & 8 & 14 \\
\hline & amarela & 1 & 1 & 0 & 0 \\
\hline & parda & 45 & 34 & 44 & 41 \\
\hline & Total & 100 & 100 & 100 & 100 \\
\hline \multirow[t]{6}{*}{1999} & indígena & 0 & 0 & 0 & 0 \\
\hline & branca & 46 & 73 & 47 & 73 \\
\hline & preta & 8 & 3 & 7 & 1 \\
\hline & amarela & 0 & 2 & 0 & 0 \\
\hline & parda & 46 & 22 & 46 & 26 \\
\hline & Total & 100 & 100 & 100 & 100 \\
\hline
\end{tabular}

Fonte: elaborado a partir de IBGE (1992, 1996 e 1999)

Entre os aposentados de ambos os sexos, com rendimento de aposentadoria igual a um salário mínimo, os brancos eram maioria em 1992, seguidos dos pardos e dos pretos. A partir de 1996, as percentagens dos dois primeiros grupos se aproximaram ( $45 \%$ entre os homens e $48 \%$ e $44 \%$ entre as mulheres). Tendência semelhante é observada no ano de 1999. Este resultado sugere que a distinção na concessão das aposentadorias pelo viés da cor (ou raça) entre os beneficiados com rendimento de aposentadoria igual a um salário mínimo diminuiu significativamente na década de 1990, mas era nítida no início da década.

Para os aposentados com rendimento de aposentadoria maior que um salário mínimo, observa-se que, em 1992, os pardos eram predominantes, tanto entre os homens quanto entre as mulheres. Em 1996 os brancos 
passaram a ser maioria, com $58 \%$ de representatividade entre os homens e $45 \%$ entre as mulheres. Em 1999 a participação dos brancos em ambos os grupos aumentou ainda mais, alcançando, nos dois casos, $73 \%$.

Desse modo, se entre os aposentados que receberam um salário mínimo de rendimento de aposentadoria o benefício teve uma melhor distribuição ao longo da década de 1990, entre aqueles que receberam mais de um salário mínimo a tendência foi oposta.

Para completar a análise, considerou-se o total de pessoas idosas em cada grupo de cor (ou raça), dividindo-os em aposentados e não aposentados. Apenas brancos e negros (que soma os pretos e pardos) foram considerados (Tabela 6).

Tabela 6 - Distribuição percentual de homens aposentados e não aposentados com residência na zona rural, por cor (ou raça) - Brasil - anos selecionados

\begin{tabular}{|c|c|c|c|c|c|}
\hline \multirow{2}{*}{ Ano } & \multirow{2}{*}{ Cor } & \multicolumn{2}{|c|}{ Renda de Aposentadoria } & \multirow{2}{*}{$\begin{array}{c}\text { Não } \\
\text { Aposentados }\end{array}$} & \multirow{2}{*}{ Tota } \\
\hline & & $=1$ sal. $\mathrm{min}$ & $>1$ sal. min. & & \\
\hline \multirow[t]{2}{*}{1992} & branca & 41 & 29 & 30 & 100 \\
\hline & negra & 25 & 41 & 34 & 100 \\
\hline \multirow[t]{2}{*}{1996} & branca & 70 & 9 & 21 & 100 \\
\hline & negra & 71 & 5 & 24 & 100 \\
\hline \multirow[t]{2}{*}{1999} & branca & 72 & 10 & 18 & 100 \\
\hline & negra & 75 & 3 & 22 & 100 \\
\hline
\end{tabular}

Fonte: elaborado a partir de IBGE (1992, 1996 e 1999)

Nota: os negros são os que se declaram pretos ou pardos.

Nas percentagens da Tabela 6, para os homens aposentados com rendimento de aposentadoria igual a um salário mínimo e residência na zona rural, observa-se que, em 1992, os brancos tinham maior participação que os negros. Em 1996, ambos os grupos aumentaram a sua participação - 29 pontos percentuais entre os brancos e 46 pontos percentuais entre os negros -, diminuindo a diferença observada em 1992. As percentagens permaneceram próximas em 1999. Observa-se ainda que, a partir de 1996, as aposentadorias no valor de um salário mínimo passaram a ser predominantes no campo (ver Tabela 1 na seção 4).

Os homens aposentados com rendimento de aposentadoria maior que um salário mínimo iniciaram a década com maior participação en- 
tre os negros (41\%) do que entre os brancos (29\%). Apesar dos aposentados com mais de um salário mínimo terem sofrido redução na participação entre os aposentados de 1992 para 1996, a queda de participação, entre os negros, de aposentados com mais de um salário mínimo de rendimento de aposentadoria foi mais acentuada, deixando de ser, inclusive, o mais representativo do grupo. Em 1999, observa-se que entre os brancos aposentados há maior proporção dos que receberam mais de um salário mínimo de rendimento de aposentadoria (10\%) do que entre os negros aposentados (3\%).

Quanto à importância dos homens não aposentados entre os idosos, embora sua tendência tenha sido de queda na década de 1990, entre os negros, os não aposentados sempre foram mais representativos. Em 1992, 30\% dos brancos idosos e 34\% dos negros idosos não eram aposentados. Em 1999, estas percentagens foram $18 \%$ e $22 \%$, respectivamente. Esse resultado é um indicativo de que pode existir favorecimento de um determinado grupo em função de sua cor (ou raça) na concessão de aposentadorias pagas no meio rural, o que não significa que a cor (ou raça) foi propriamente o fator de exclusão, e sim as condições socioeconômicas desse grupo.

A Tabela 7 utilizou a mesma metodologia que a tabela anterior para apresentar a análise da classificação das mulheres idosas com residência na zona rural por cor (ou raça). Para as mulheres, o primeiro ponto a ser destacado é que, no início da década de 1990, a maior parte delas não era incluída como beneficiária da aposentadoria por idade, o que explica a baixa participação das aposentadas entre as mulheres idosas em 1992. A partir de 1996, as aposentadas com rendimento de aposentadoria igual a um salário mínimo passaram a ser maioria, tanto entre as idosas brancas quanto entre as idosas negras. No ano de 1999, as aposentadas com este mesmo rendimento atingiram seus níveis de participação mais elevados ( $63 \%$ entre as idosas brancas e $64 \%$ entre as idosas negras).

Analisando as aposentadas com rendimento de aposentadoria maior que um salário mínimo, por cor (ou raça), constata-se que estas aposentadas eram mais representativas entre as negras do que entre as brancas em 1992. O inverso ocorre em 1999.

As não aposentadas, por motivos já mencionados na seção 3 , foram as mais representativas em 1992, com maior importância entre as 
brancas (62\%) do que entre as negras (59\%). A partir de 1996, ambas tiveram queda, sendo que, em 1999, a importância das não aposentadas entre as idosas brancas (34\%) e entre as idosas negras (35\%) foram próximas. Tal como no caso dos homens, a distinção na obtenção de aposentadoria pelas mulheres segundo a cor é nítida o início da década de 1990 e esse viés diminui com o passar do tempo.

Tabela 7 - Distribuição percentual de mulheres aposentadas e não aposentadas com residência na zona rural, por cor (ou raça) Brasil - anos selecionados

\begin{tabular}{|c|c|c|c|c|c|}
\hline \multirow{2}{*}{ Ano } & \multirow{2}{*}{ Cor } & \multicolumn{2}{|c|}{ Renda de Aposentadoria } & \multirow{2}{*}{$\begin{array}{c}\text { Não } \\
\text { Aposentadas }\end{array}$} & \multirow{2}{*}{ Total } \\
\hline & & $=1$ sal. $\min$ & $>1$ sal. min. & & \\
\hline \multirow[t]{2}{*}{1992} & branca & 21 & 17 & 62 & 100 \\
\hline & negra & 16 & 25 & 59 & 100 \\
\hline \multirow[t]{2}{*}{1996} & branca & 62 & 3 & 35 & 100 \\
\hline & negra & 59 & 3 & 38 & 100 \\
\hline \multirow[t]{2}{*}{1999} & branca & 63 & 3 & 34 & 100 \\
\hline & negra & 64 & 1 & 35 & 100 \\
\hline
\end{tabular}

Fonte: elaborado a partir de IBGE (1992, 1996 e 1999)

Apesar dos não aposentados terem sofrido queda de participação entre os idosos de cada cor (ou raça) ao longo da década de 1990, ainda é significativo seu percentual entre idosos que poderiam obter os benefícios da previdência social. Comparando-os por sexo, observa-se que as idosas não aposentadas em 1999 continuaram com percentagens altas (34\% entre as brancas e $35 \%$ entre as negras). As participações dos não aposentados entre os homens idosos foram menores: $18 \%$ entre os brancos e $22 \%$ entre os negros. Esse resultado pode representar um indicativo de maior facilidade dos homens se aposentarem, em detrimento das mulheres.

\subsection{Análise da escolaridade dos aposentados com residência na zona rural}

A análise do grau de escolaridade foi feita entre os idosos aposentados e os não aposentados com residência na zona rural, segundo a seguinte 
classificação adotada no Brasil: sem instrução ou com menos de um ano de estudo; de um a quatro anos, que corresponde à primeira metade do ensino fundamental; de cinco a oito anos, que corresponde à segunda metade do ensino fundamental; e maior que oito anos de estudo ${ }^{18}$. A Tabela 8 apresenta a distribuição percentual de homens e mulheres aposentados e não aposentados com residência na zona rural, por sexo, nível de escolaridade e rendimento de aposentadoria. Calcularam-se as percentagens de aposentados e não aposentados considerando o somatório dos diferentes níveis de escolaridade para cada ano igual a $100 \%$.

De acordo com a Tabela 8, é possível observar que, ao longo da década de 1990, houve melhora no número de anos de estudo completos tanto entre os aposentados quanto entre os não aposentados, embora a grande maioria deles tenha sido classificada nos dois primeiros níveis de escolaridade. Para as mulheres aposentadas sem instrução ou com menos de um ano de estudo e com rendimento de aposentadoria maior que um salário mínimo, a queda na participação das pouco letradas entre 1992 e 1999 foi de 75 pontos percentuais. Para as aposentadas com mesmo nível de escolaridade e com rendimento igual a um salário mínimo, a queda foi de 16 pontos percentuais. As mulheres não aposentadas e com menos de um ano de instrução também mostraram a mesma tendência, saindo de 80\% em 1992 para 58\% em 1999. É importante observar que, nos três casos, a queda no primeiro nível de escolaridade veio acompanhada de aumento da participação das mulheres no segundo nível de instrução. As aposentadas com rendimento maior que um salário mínimo também tiveram crescimento nos dois últimos níveis de escolaridade.

Entre os homens, observa-se a mesma tendência. Tanto os aposentados quanto os não aposentados apresentaram melhora no nível de escolaridade, com redução da importância dos idosos sem instrução ou com menos de um ano de estudo entre os aposentados.

Observa-se que os aposentados(as) com rendimento de aposentadoria maior que um salário mínimo foram mais instruídos do que os aposentados que receberam um salário mínimo de rendimento de aposentadoria. Observa-se também que os analfabetos (com menos de um ano

${ }^{18} \mathrm{Na}$ análise da escolaridade estão sendo considerados apenas os anos de estudo completos.

RER, Rio de Janeiro, vol. 44, no 03, p. 467-502, jul/set 2006 - Impressa em setembro 2006 
de estudo) foram sempre mais representativos entre os aposentados e aposentadas que receberam um salário mínimo de rendimento de aposentadoria do que entre os aposentados e aposentadas que receberam aposentadoria maior que um salário mínimo. Esse resultado comprova que o aumento do número de anos de escolaridade leva a pessoa a obter melhores salários e, conseqüentemente, maior inserção no mercado de trabalho. A participação no mercado formal propicia aos trabalhadores valores de aposentadoria superiores na velhice.

Tabela 8 - Distribuição percentual de aposentados e não aposentados com residência na zona rural, por sexo e nível de escolaridade - Brasil - anos selecionados

\begin{tabular}{|c|c|c|c|c|c|c|c|}
\hline & \multicolumn{4}{|c|}{ Homens } & \multicolumn{3}{|c|}{ Mulheres } \\
\hline \multirow{2}{*}{ Ano } & \multirow{2}{*}{$\begin{array}{c}\text { Nível de } \\
\text { Escolaridade } \\
\text { (em Anos de } \\
\text { Estudo) } \\
\end{array}$} & \multicolumn{2}{|c|}{$\begin{array}{c}\text { Renda de } \\
\text { Aposentadoria }\end{array}$} & \multirow[t]{2}{*}{$\begin{array}{c}\text { Não } \\
\text { Aposentados }\end{array}$} & \multicolumn{2}{|c|}{$\begin{array}{c}\text { Renda de } \\
\text { Aposentadoria }\end{array}$} & \multirow[t]{2}{*}{$\begin{array}{c}\text { Não } \\
\text { Aposentadas }\end{array}$} \\
\hline & & $\begin{array}{l}=1 \mathrm{sal} . \\
\text { min. }\end{array}$ & $\begin{array}{l}>1 \text { sal. } \\
\text { min. }\end{array}$ & & $\begin{array}{l}=1 \mathrm{sal} \\
\text { min. }\end{array}$ & $\begin{array}{l}>1 \mathrm{sal} \\
\text { min. }\end{array}$ & \\
\hline \multirow{5}{*}{1992} & $\begin{array}{c}\text { s/ instrução ou } \\
<1 \text { ano }\end{array}$ & 78 & 86 & 79 & 81 & 93 & 80 \\
\hline & 1 a 4 anos & 18 & 12 & 19 & 17 & 6 & 18 \\
\hline & 5 a 8 anos & 4 & 1 & 2 & 2 & 0 & 2 \\
\hline & $>8$ anos & 0 & 1 & 0 & 0 & 1 & 0 \\
\hline & Total & 100 & 100 & 100 & 100 & 100 & 100 \\
\hline \multirow{5}{*}{1996} & $\begin{array}{l}\text { s/ instrução ou } \\
<1 \text { ano }\end{array}$ & 80 & 58 & 75 & 79 & 70 & 76 \\
\hline & 1 a 4 anos & 19 & 29 & 21 & 19 & 12 & 21 \\
\hline & 5 a 8 anos & 1 & 10 & 3 & 2 & 6 & 2 \\
\hline & $>8$ anos & 0 & 3 & 1 & 0 & 12 & 1 \\
\hline & Total & 100 & 100 & 100 & 100 & 100 & 100 \\
\hline \multirow{5}{*}{1999} & $\begin{array}{c}\text { s/ instrução ou } \\
<1 \text { ano }\end{array}$ & 66 & 20 & 57 & 65 & 18 & 58 \\
\hline & 1 a 4 anos & 31 & 55 & 36 & 31 & 35 & 35 \\
\hline & 5 a 8 anos & 3 & 15 & 5 & 4 & 14 & 5 \\
\hline & $>8$ anos & 0 & 10 & 2 & 0 & 33 & 2 \\
\hline & Total & 100 & 100 & 100 & 100 & 100 & 100 \\
\hline
\end{tabular}

Fonte: elaborado a partir de IBGE (1992, 1996 e 1999) 
A distribuição dos aposentados(as) segundo a escolaridade e cor (ou raça) está na Tabela 9. Ao fazer essa combinação, considerou-se apenas os dois grupos mais representativos entre os homens e mulheres aposentados com residência na zona rural, a saber: os brancos e os negros. Observa-se que a maioria dos aposentados negros de ambos os sexos permaneceu sem instrução ao longo da década de 1990. Entre os brancos também foi grande a participação daqueles sem instrução ou com menos de um ano de estudo, porém, se comparados aos negros, as percentagens foram bem inferiores. Em 1999, entre os homens brancos aposentados, $53 \%$ tinham menos de um ano de escolaridade e, entre os negros aposentados, esta participação foi de $78 \%$. Para as mulheres, essas percentagens foram $51 \%$ e $77 \%$, respectivamente.

Outro indicador do maior nível de instrução dos aposentados brancos em relação aos aposentados negros é a análise da concentração no segundo e no terceiro nível de educação colocada na Tabela 9. A percentagem é sempre maior entre os brancos, para todos os anos e ambos os sexos, do que entre os negros. Em 1999, 42\% dos idosos brancos aposentados tinham de 1 a 4 anos de estudo completos e, entre os idosos negros aposentados, apenas $21 \%$ tinham este nível de escolaridade. Essas percentagens para as mulheres foram, respectivamente, $41 \%$ e $21 \%$.

Entre os homens e mulheres aposentados com rendimento de aposentadoria maior que um salário mínimo, a melhora no nível educacional tanto entre brancos quanto entre negros foi ainda mais expressiva. As mulheres brancas sem instrução ou com menos de um ano de estudo, por exemplo, iniciaram a década com $80 \%$ de participação entre as aposentadas recebendo mais de um salário mínimo de rendimento de aposentadoria. Este mesmo grupo chegou a 1999 com apenas 14\% . As mulheres negras com mesmo nível de escolaridade participaram com $91 \%$ em 1992, enquanto que, em 1999, elas representaram apenas $28 \%$. Mas, mesmo assim, as aposentadas e os aposentados brancos eram mais instruídos que os negros entre os que receberam mais de um salário mínimo de rendimento de aposentadoria.

Portanto, através da classificação por cor (ou raça) nos diferentes níveis de educação é possível observar que os aposentados negros permaneceram com níveis de escolaridade inferiores se comparados aos aposentados brancos. Esse resultado reflete, de certa forma, condições 
socioeconômicas distintas vivenciadas por ambos os grupos, onde, em média, os brancos têm maior acesso ao sistema educacional. E, como o maior grau de instrução facilita a requisição de qualquer benefício previdenciário, esta pode ser uma das razões para a maior participação dos brancos no sistema de aposentadorias.

Tabela 9 - Distribuição percentual de aposentados com residência na zona rural, por sexo, cor (ou raça) e escolaridade - Brasil - anos selecionados

\begin{tabular}{|c|c|c|c|c|c|c|c|c|}
\hline \multirow{2}{*}{ Cor } & \multirow{2}{*}{$\begin{array}{c}\text { Renda de } \\
\text { Aposentadoria }\end{array}$} & \multirow{2}{*}{$\begin{array}{c}\text { Escolaridade } \\
\text { (em Anos de } \\
\text { Estudo) }\end{array}$} & \multicolumn{2}{|c|}{1992} & \multicolumn{2}{|c|}{1996} & \multicolumn{2}{|c|}{1999} \\
\hline & & & Homens & Mulheres & Homens & Mulheres & Homens & Mulheres \\
\hline \multirow{10}{*}{$\begin{array}{l}\tilde{U} \\
\stackrel{0}{0}\end{array}$} & $=1$ sal. min. & $\begin{array}{c}\text { s/ instrução } \\
\text { ou }<1\end{array}$ & 52 & 55 & 53 & 53 & 53 & 51 \\
\hline & & de 1 a 4 & 43 & 40 & 44 & 42 & 42 & 41 \\
\hline & & de 5 a 8 & 5 & 5 & 3 & 5 & 5 & 8 \\
\hline & & $>8$ & 0 & 0 & 0 & 0 & 0 & 0 \\
\hline & & Total & 100 & 100 & 100 & 100 & 100 & 100 \\
\hline & > 1 sal. min & $\begin{array}{c}\text { s/ instrução } \\
\text { ou }<1\end{array}$ & 61 & 80 & 29 & 29 & 16 & 14 \\
\hline & & de 1 a 4 & 32 & 14 & 48 & 30 & 57 & 40 \\
\hline & & de 5 a 8 & 4 & 2 & 16 & 10 & 17 & 12 \\
\hline & & $>8$ & 3 & 4 & 7 & 31 & 10 & 34 \\
\hline & & Total & 100 & 100 & 100 & 100 & 100 & 100 \\
\hline \multirow{10}{*}{$\begin{array}{l}\frac{\pi}{6} \\
\stackrel{\infty}{\infty} \\
z\end{array}$} & $=1$ sal. $\min$ & $\begin{array}{c}\text { s/ instrução } \\
\text { ou }<1\end{array}$ & 81 & 84 & 79 & 78 & 78 & 77 \\
\hline & & de 1 a 4 & 17 & 14 & 20 & 20 & 21 & 21 \\
\hline & & de 5 a 8 & 2 & 1 & 1 & 2 & 1 & 2 \\
\hline & & $>8$ & 0 & 1 & 0 & 0 & 0 & 0 \\
\hline & & Total & 100 & 100 & 100 & 100 & 100 & 100 \\
\hline & $>1$ sal. min & $\begin{array}{c}\text { s/ instrução } \\
\text { ou }<1\end{array}$ & 85 & 91 & 62 & 82 & 32 & 28 \\
\hline & & de 1 a 4 & 14 & 9 & 31 & 3 & 49 & 22 \\
\hline & & de 5 a 8 & 1 & 0 & 6 & 10 & 8 & 19 \\
\hline & & $>8$ & 0 & 0 & 1 & 5 & 11 & 31 \\
\hline & & Total & 100 & 100 & 100 & 100 & 100 & 100 \\
\hline
\end{tabular}

Fonte: elaborado a partir de IBGE (1992, 1996 e 1999) 


\subsection{Análise econométrica}

Para mensurar o impacto da escolaridade, da cor (ou raça) e do sexo na condição do idoso estar ou não aposentado, foi utilizado o modelo Próbite, em que a variável dependente é igual a um (1) se o idoso é aposentado e igual a zero (0) se ele não é aposentado. Foram estabelecidas duas equações distintas segundo o valor da aposentadoria dos idosos e estimadas em cada ano de análise. A primeira equação considerou com valor um (1) os aposentados com rendimento de aposentadoria igual a um salário mínimo. Na segunda, apenas os aposentados com rendimento maior que um salário mínimo foram considerados. Entre os idosos(as), selecionaram-se os homens com 60 anos ou mais e as mulheres com 55 anos ou mais, ambos com residência na zona rural. Todas as regressões foram ponderadas pelo fator de expansão da amostra das PNADs e estimadas usando o software STATA.

A Tabela 10 apresenta os resultados obtidos dos efeitos marginais do modelo Próbite para as equações estimadas. A coluna (A) considera o primeiro grupo descrito no parágrafo anterior. Da mesma forma, a coluna (B) o segundo grupo. Para a variável escolaridade foram considerados apenas os anos de estudo completos. Já a binária referente à cor (ou raça) analisa os brancos (igual a um) e os negros (igual a zero), considerando como negros os idosos que se declararam pretos ou pardos. Na binária sexo, considerou-se um para os homens e zero para as mulheres.

A primeira variável de interesse, escolaridade, apresentou-se estatisticamente significativa a $1 \%$, sendo exceção apenas o grupo (A) em 1992. Para o grupo (A) - aposentados com rendimento de aposentadoria igual a um salário mínimo -, observa-se que o sinal esperado para a escolaridade é negativo, porque quanto maior o número de anos de estudo, maior a probabilidade do idoso residente na zona rural obter aposentadoria maior que um salário mínimo e menor a sua probabilidade de obter aposentadoria igual a um salário mínimo. Analogamente, no grupo (B) - aposentados com rendimento de aposentadoria maior que um salário mínimo - o resultado esperado para o sinal da escolaridade é positivo. Os sinais da variável escolaridade foram os esperados em todas as regressões, exceto para o grupo (B) em 1992.

A segunda variável de interesse, cor (ou raça) do idoso, apresentou-se 
estatisticamente significativa a $1 \%$ em todos os anos selecionados, exceto entre os idosos do grupo (B) de 1996, em que a significância ficou ao nível de $10 \%$. Neste caso, observa-se que na grande maioria dos grupos houve favorecimento dos brancos em relação aos negros, sendo exceção o grupo (B) em 1992. Isso significa que, entre os idosos residentes na zona rural, ser branco foi uma condição relevante no aumento da probabilidade de se aposentar, independente do valor da aposentadoria.

Tabela 10 - Efeitos marginais do modelo Próbite para idosos aposentados com 60 anos de idade ou mais, se homens, e 55 anos de idade ou mais, se mulheres, com residência na zona rural - Brasil - anos selecionados

\begin{tabular}{llcc}
\hline \multirow{2}{*}{ Ano } & \multirow{2}{*}{ Variável } & \multicolumn{2}{c}{ Renda de Aposentadoria } \\
\cline { 3 - 4 } & & $=1$ sal. Mín. (A) & $>1$ sal. Mín. (B) \\
\hline \multirow{2}{*}{1992} & Escolaridade & $-0,0060(0,0045)^{* * *}$ & $-0,0238(0,0057)^{*}$ \\
& Cor (branca) & $0,0916(0,0156)^{*}$ & $-0,0698(0,0158)^{*}$ \\
& Sexo (masc.) & $0,2684(0,0154)^{*}$ & $0,2701(0,0155)^{*}$ \\
\hline \multirow{2}{*}{1996} & Escolaridade & $-0,0178(0,0035)^{*}$ & $0,0196(0,0027)^{*}$ \\
& Cor (branca) & $0,0456(0,0135)^{*}$ & $0,0291(0,0154)^{* *}$ \\
& Sexo (masc.) & $0,1318(0,0128)^{*}$ & $0,1671(0,0178)^{*}$ \\
\hline \multirow{2}{*}{1999} & Escolaridade & $-0,0234(0,0031)^{*}$ & $0,0228(0,0022)^{*}$ \\
& Cor (branca) & $0,0375(0,0123)^{*}$ & $0,0599(0,0132)^{*}$ \\
& Sexo (masc.) & $0,1354(0,0116)^{*}$ & $0,1575(0,0164)^{*}$ \\
\hline
\end{tabular}

Fonte: elaborado a partir de IBGE (1992, 1996 e 1999)

Nota: os desvios-padrão encontram-se entre parênteses

* Denota significância ao nível de 1\%

** Denota significância ao nível de $10 \%$

*** Não significativo

Quanto à variável sexo, observa-se que o fato do idoso ser homem também o favoreceu na concessão de aposentadorias no mesmo período. Esta tendência é mais perceptível entre os aposentados com rendimento de aposentadoria maior que um salário mínimo.

Assim, a análise dos efeitos marginais (Tabela 10) indica que a variável que mais acresceu probabilidade de um idoso estar aposentado no meio rural foi o sexo, seguido da cor (ou raça). No entanto, os efeitos marginais são decrescentes ao longo da década de 1990. Em 1999, por exemplo, o fato do idoso ser homem aumentava em 13,54 pontos 
percentuais a sua probabilidade de estar aposentado com um salário mínimo de rendimento de aposentadoria em relação à probabilidade da mulher. Sendo branco, sua probabilidade de estar aposentado era 3,75 pontos percentuais acima da probabilidade do negro. E a cada ano de escolaridade, reduzia-se em $2,34 \%$ a sua probabilidade de estar aposentado com um salário mínimo.

Os resultados da Tabela 10 complementam as análises feitas no início da seção, em que foi traçado o perfil dos aposentados residentes no meio rural, baseando-se na análise tabular da escolaridade e da cor (ou raça) dos mesmos. Assim, é possível verificar que, apesar da previdência social ter reduzido a pobreza e ter gerado menos desigualdade na distribuição da renda entre os beneficiados durante a década de 1990, ela não foi eqüitativa, pois acabou sendo concedida principalmente às pessoas com maior nível de escolaridade e às que se declararam de cor branca.

Provavelmente, esse viés não foi gerado pelas regras da Previdência Rural, mas sim pelo ambiente social em que vivem os possíveis candidatos a requerer os benefícios da Previdência. Os homens, normalmente, participam com maior freqüência do mercado de trabalho rural do que as mulheres tendo, com isso, maior chance de comprovarem esse exercício, o que é essencial para obter a aposentadoria por idade. Os indivíduos brancos são, normalmente, mais instruídos que os negros e, por isso, o idoso branco se relaciona com indivíduos que o auxilia na obtenção de seus direitos. Isto não ocorre com os idosos negros, pois o seu círculo de relacionamento ocorre com pessoas menos instruídas.

\section{Conclusões}

O objetivo deste trabalho foi avaliar a eqüidade do sistema de aposentadorias pagas no meio rural. Entende-se por eqüidade a ausência de favorecimento no acesso aos benefícios por questões de sexo, cor (ou raça) e nível de educação.

A Constituição Federal de 1988 instituiu o princípio da universalização e, com ele, ocorreram mudanças significativas na legislação previdenciária dos trabalhadores rurais. Pode-se citar como principais mudanças a criação de um piso mínimo para os benefícios, garantindo o recebimento de pelo menos um salário mínimo; a fixação de idades dife- 
renciadas para o requerimento da aposentadoria por idade ( 55 anos para as mulheres e 60 anos para os homens); e a igualdade de direitos entre trabalhadores e trabalhadoras rurais, deixando de excluir as mulheres casadas ou com vida conjugal ao acesso dos benefícios previdenciários.

Este trabalho destacou os aposentados com rendimento de aposentadoria igual a um salário mínimo - proxy dos aposentados por idade - porque verificou-se que, na década de 1990, eles passaram a representar a maioria dos aposentados no campo. Esse contingente foi comparado com os aposentados que receberam mais de um salário mínimo de rendimento de aposentadoria e com os idosos não aposentados que viviam na zona rural.

Conclui-se que a previdência social contribuiu para o aumento dos níveis de renda no campo sem aumentar a desigualdade de distribuição dessa renda. Com o resultado dos cálculos do índice de Gini para a renda familiar per capita, observou-se que, para todos os grupos de aposentados com residência na zona rural e ambos os sexos, houve menor desigualdade entre os aposentados do que entre os não aposentados. De um modo geral, os homens e mulheres aposentados com rendimento de aposentadoria maior que um salário mínimo tiveram renda familiar per capita superior aos dos não aposentados. Ao final da década de 1990 não se encontravam diferenças expressivas entre os homens e mulheres no recebimento de aposentadorias, mas esta diferença foi constatada no início da década.

Através da análise tabular dos dados das PNADs (1992, 1996 e 1999), observou-se que os homens brancos foram favorecidos durante a década na obtenção dos benefícios previdenciários em relação aos negros, em especial nas aposentadorias superiores a um salário mínimo. Por outro lado, o nível de escolaridade foi um fator determinante na concessão do benefício. Entre os aposentados, observou-se redução na participação daqueles sem instrução ou com menos de um ano de estudo, e aumento no nível de escolaridade seguinte, correspondente à primeira metade do ensino fundamental. Ao se fazer a análise dos níveis de escolaridade dos brancos e negros, os dois grupos mais representativos na classificação por cor (ou raça), observou-se que, quanto mais alto foi o grau de instrução, maior foi a participação dos brancos. Este resultado sugere que o sistema de previdência social não teve cará- 
ter de favorecimento per se, mas a dificuldade de outros grupos de cor (ou raça) terem acesso à educação, como o de pretos e o de pardos, por exemplo, implicou dificuldade no requerimento de seus direitos, como foi o caso da previdência social na década de 1990. A aposentadoria, sob esse aspecto, reflete as distintas condições socioeconômicas vivenciadas por ambos os grupos.

As análises do favorecimento da concessão das aposentadorias por sexo, cor (ou raça) e escolaridade foram consolidadas através da estimativa do modelo Próbite. Dividindo os aposentados em duas categorias (os que recebiam um salário mínimo de rendimento de aposentadoria e os que recebiam mais de um salário mínimo de aposentadoria), constatou-se que os homens apresentaram maior probabilidade de estarem aposentados, se comparados com as mulheres. Os brancos, independentes do sexo e nível de escolaridade, apresentaram maior probabilidade de estarem aposentados. E, quanto maior é o nível de escolaridade, menor é a probabilidade do idoso (ou idosa) se aposentar com rendimento de um salário mínimo.

A conclusão geral do trabalho é que, durante a década de 1990, a previdência social elevou a renda per capita no campo, através do pagamento de benefícios, e gerou menor desigualdade na distribuição da renda entre as famílias dos beneficiados do que entre a dos não beneficiados. Os idosos, que na inatividade se encontravam na condição de dependentes, passaram, a partir do sistema de aposentadorias, a ser participantes da renda familiar. No entanto, a previdência social não foi eqüitativa, pois por questões já mencionadas acabou favorecendo mais os idosos com maior nível de escolaridade e os brancos.

Como sugestão para melhorar a eqüidade da previdência social no campo, especialmente no caso dos trabalhadores rurais, têm-se a simplificação dos seus procedimentos burocráticos de modo a ampliar o acesso de idosos aos benefícios previdenciários, a criação de serviços públicos de ajuda ao potencial beneficiário e, no longo prazo, investir em programas de alfabetização no campo - programas que beneficiem adultos e crianças. Como, a partir de 2006, certo número mínimo de meses de contribuição previdenciária vai passar a ser obrigatório para o requerimento da aposentadoria por idade, é importante que se promovam campanhas de conscientização da importância do comprovante 
de comercialização agrícola (no qual se inclui a contribuição previdenciária), principalmente entre os trabalhadores que trabalham por conta própria. Assim, o trabalhador rural continuará tendo condições de requerer a aposentadoria por idade.

\section{Referências bibliográficas}

ABRANCHES, S. Questão social, uma previdência e cidadania no Brasil. In: GOMES, A.C. (Org.). Trabalho e previdência: 60 anos em debate. Rio de Janeiro: Ed. da Fundação Getúlio Vargas/CPDOC, 1992. p.78-91.

BARROS, R.P.; MENDONÇA, R.S.P.; DUARTE, R.P.N. Bem-estar, pobreza e desigualdade de renda: uma avaliação da evolução histórica e das disparidades regionais. Brasília: IPEA, 1997. 59p. (Texto para Discussão, 454)

BELTRÃO, K.; OLIVEIRA, F.E.B.; PINHEIRO, S.S. A população rural e a previdência social no Brasil: uma análise com ênfase nas mudanças constitucionais. Brasília: IPEA, 2000a. 26p. (Texto para Discussão, 759)

BELTRÃO, K.; OLIVEIRA, F.E.B.; SOUZA, M.C.; MENDONÇA, J.L.O.; GOMES, L.P.C.S. MAPS: uma versão amigável do modelo demográficoatuarial de projeções e simulações de reformas previdenciárias do IPEA/ IBGE. Rio de Janeiro: IPEA, 2000b. 48p. (Texto para Discussão, 774)

BRASIL. Constituição da República Federativa do Brasil. Rio de Janeiro: Ed. Saraiva, 1988. 331p.

BRASIL. Ministério da Previdência e Assistência Social. Suplemento histórico. http://www.mpas.gov.br/12_01_20.asp (21 ago. 2003)

CORRÊA, A.M.C.J. Distribuição de rendimentos e pobreza na agricultura brasileira 1981-1990. Piracicaba, 1995. 353p. Tese (Doutorado) - Escola Superior de Agricultura “Luiz de Queiroz”, Universidade de São Paulo.

DELGADO, G.C. Relatório metodológico da pesquisa avaliação socioeconômica e regional da previdência social rural fase II. Brasília: IPEA, 1999. 132p.

DELGADO, G.C.; SCHWARZER, H. Evolução histórico-legal e formas de financiamento da previdência rural no Brasil. In: DELGADO, G.C. 
(Org.). A universalização de direitos sociais no Brasil: a previdência rural nos anos 90. Brasília: IPEA, 2000. p.23-41.

DELGADO, G.; CARDOSO JUNIOR, J.C. O idoso e a previdência social rural no Brasil: a experiência recente da universalização. Brasília: IPEA, 2000. 28p. (Texto para Discussão, 688)

DEUD, C.A.F.; MALVAR, R.H.V.P. A mulher e a previdência social. Brasília: CEPAL/MPS, 1993. 247p.

FARO, C. A questão da previdência e da assistência social: breve histórico da evolução do sistema previdenciário. In: GOMES, A.C. (Org.). Trabalho e previdência: 60 anos em debate. Rio de Janeiro: Ed. da Fundação Getúlio Vargas/CPDOC, 1992. p.69-73.

FAUSTO NETO, A.M.Q. Família operária e a reprodução da força de trabalho. Petrópolis: Vozes, 1982. 187p.

FERREIRA, C.R. Participação das aposentadorias e pensões na desigualdade da distribuição da renda no Brasil no período de 1981 a 2001. Piracicaba, 2003. 135p. Tese (Doutorado) - Escola Superior de Agricultura "Luiz de Queiroz", Universidade de São Paulo.

HOFFMANN, R. Desigualdade no Brasil: a contribuição das aposentadorias. http://www.eco.unicamp.br /projetos/rurbano.html (21 dez. 2002)

HOFFMANN, R. Distribuição de renda: medidas de desigualdade e pobreza. São Paulo: Edusp, 1998. 275p.

INSTITUTO BRASILEIRO DE GEOGRAFIA E ESTATÍSTICA (IBGE). Pesquisa nacional por amostra de domicílios (compact disc). Rio de Janeiro, 1992, 1996 e 1999.

INSTITUTO BRASILEIRO DE GEOGRAFIA E ESTATÍSTICA (IBGE). Sidra. http://www.sidra.ibge.gov.br/bda/ (05 mar. 2001)

INTERNATIONAL SOCIAL SECURITY ASSOCIATION (ISSA). Social security programs throughout the world. http://www.ssa.gov/policy/ docs/progdesc/ (20 Feb. 2004)

JAMES, E. New models for old-age security: experiments, evidence, and unanswered questions. The World Bank Research Observer, v.13, n.2, p.230-241, Aug. 1998. 
MACCALÓZ, S.M.P.; MELO, H.P. A reforma da previdência e a condição feminina. São Paulo: AJUFE, 1997. 112p.

MÉDICI, A.C.; BELTRÃO, K.I.; OLIVEIRA, F.E.B. Mulher e previdência social. Rio de Janeiro: IBGE/ENCE, 1994. 63p. (Série Relatórios Técnicos)

MELO, H.P. 0 trabalho feminino no mundo rural. Niterói: Universidade Federal Fluminense, 2000. 84p. (Texto para Discussão, 140/00)

SCHWARZER, H. Paradigmas de previdência social rural: um panorama da experiência internacional. Brasília: IPEA, 2000. 49p. (Texto para Discussão, 767).

Recebido em dezembro de 2005 e revisto em maio de 2006 